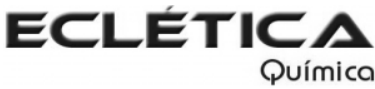

www.scielo.br/eq

www.ecletica.iq.unesp.br

Volume 32, número 4, 2007

\title{
Allelopathic potential and systematic evaluation of secondary compounds in extracts from roots of Canavalia ensiformis by capillary electrophoresis
}

\author{
S. Santos, M. L. L. Moraes, M. O. O. Rezende \\ ${ }^{I}$ Universidade de São Paulo, Instituto de Química de São Carlos, Av. Trabalhador São Carlense 400, \\ CEP.13560-970, CP. 780, São Carlos - SP - Brasil.
}

\begin{abstract}
Organic extracts were obtained from roots of Canavalia ensiformis and evaluated for allelopathic potential on the germination of the weed seeds: Mimosa pudica, Cassia tora and Cassia occidentalis showing a strong allelopathic potential. After that, a systematic study of these crude extracts was made using specific protocols developed in capillary electrophoresis (CE) in order to determine some classes of secondary metabolites. Capillary electrophoresis protocols were highly specific, which makes it possible to identify 5 classes of compounds using the same crude extract samples and analyze them fartly. Some of the compounds identified show activity in the inhibition of seeds germination.
\end{abstract}

Keywords: allelopathy; capillary electrophoresis; Canavalia ensiformis; roots.

\section{Introduction}

Several hundred chemicals have been used to manufacture agrochemicals. However, the use of many of these chemicals is a cause of concern from both environmental and health points of view. These hazards are largely attributed to their non-biodegradable nature, as most of them are artificially synthetized. It has resulted in an increased interest in alternative strategies leading to the development of biodegradable compounds.

Plants are known to produce bioactive molecules (secondary compounds), which react with other organisms in the environment, inhibiting bacterial and fungal growth (antibiotic activity) or modulating the development of other vegetables (allelopathic activity) $[1,2]$. Due to their biodegradability, most of the plant products are considered to be safer for the consumers and their environment.

Canavalia ensiformis is a semi-erect annual legume with a bushy growth, originating from the New World and presently widespread throughout the tropics. It is used as a cover crop in soil erosion control and occasionally its seeds are used as foodstuff. Canavalia is relatively free from diseases, pests and weeds, turning this plant into an interesting research object $[3,4]$.

It is therefore essential to work effectively to exploit such compounds directly actuate and/or to explore the possibility of using these chemicals as molecular models to crate more active and safer products.

Some advantages of natural products as herbicide are presented below [5]:

The vast majority of natural compounds pose little health threat and probably would be environmentally safe. The half lives of most natural compounds in the environment probably are much shorter than those of synthetic compounds.

Many phytotoxins from phytopathogens have a high degree of target species selectivity that are not matched by any conventional herbicide class.

\section{Capillary Electrophoresis}

In general, separations and purifications of 
organic extracts are carried out using one or more chromatographic techniques. The use of these techniques for analysis of a great amount of compounds can be very time-consuming, though, especially when it involves complex mixtures like plant extracts [6-10].

Capillary electrophoresis (CE) is a microanalytical method that has become an extremely advantageous technique for the separation of many compounds in phytochemical analysis, mainly because it provides the possibility to inject crude extracts without previous purification or separation of the active compounds. CE provides advantages in terms of speed, high efficiency, low cost and simplicity. This technique requires small contents of electrolyte and sample, no solvents and consequently produces small amounts of residues [6-10].

Capillary electrophoresis is performed in columns with capillary dimensions $(25-75 \mu \mathrm{m}$ of internal diameter and $375 \mu \mathrm{m}$ of external diameter). The capillary is filled with an electrolyte solution, immersed in two reservoirs containing the selected electrolyte and submitted to high voltages. Samples are injected in the capillary by the controlled application of either voltage or pressure during a period of time. The compounds are separated into the column and detected by a detection system. [11].

Studying the physical-chemical interactions between the analytes and the electrolyte medium components, TAVARES et al [12] drawing several analytical protocols to phytochemical analyses that provides an instantaneous profile of the plant secondary metabolic status at the time of examination. Due to the versatility of CE technique it is possible to separate and identify specific classes of plant constituents just by using a single capillary column, selecting a proper electrolyte and $\mathrm{pH}$. The procedure for analyses using the protocols is simple and means only injecting crude extracts without previous purification under specific conditions $(\mathrm{pH}$, electrolyte, wave length) that facilitate the ionization and separation of a specific class of compounds.

In this work we assembled capillary electrophoresis protocols to carry out a systematic evaluation of organic extracts from Canavalia ensiformis roots. It were separated and identified five classes of compounds: flavonoids, alkaloids, terpenes, phenolic acids and carboxylic acids. The secondary compounds studied were chosen according to their occurrence in plant extracts and their crucial importance in allelopathic phenomenon.

\section{Materials and methods}

\section{Chemicals}

All the reagents were of analytical grade. Solvents: hexane, dichloromethane, ethyl acetate and methanol (HPLC grade) were obtained from Mallinkrodt. Deionized water was obtained from Millipore system and it was used to prepare all the solutions of the electrolytes.

Standards of the secondary compounds and the mesityl oxide were purchased from Sigma-Aldrich and the Acros Organics. Sodium dodecyl sulphate (SDS), cethyltrimethylammonium bromide (CTAB) and 3.5-dinitrobenzoate were purchased from Fluka and Mallinkrodt.

Electrolytes: sodium tetraborate and sodium phosphate were purchased from Mallinckrodt, phosphoric acid from Synth.

\section{Sample Collection}

Canavalia ensiformis roots were collected, dried and triturated in Willey mill. The vegetal material was stored in plastic containers at room temperature until further use.

Seeds of the weeds: Mimosa pudica M., Cassia occidentalis L. and Cassia tora L., known as "malícia", "fedegoso" and "mata-pasto" were chosen because they are a common problem in pastures of the state of Pará - Brazil. These seeds were collected in pastures in the cities of Castanhal and Paragominas, Pará, Brazil.

\section{Sample Preparation}

Crude extracts were prepared from $300 \mathrm{~g}$ of dry plant material and $500 \mathrm{~mL}$ of hexane. They were soaked for 7 days in mechanical stirring at room temperature. The mixture was filtered daily, the extract was concentrated in vacuum at $35^{\circ} \mathrm{C}$ and the plant material was put back into the Erlenmeyer flask with more $500 \mathrm{~mL}$ of hexane. After 7 days the mixture was filtered in the Buchner funnel, the dry plant material was returned into the Erlenmeyer flask and the solvent was changed to dichlorometane. After seven days the solvent was exchanged for ethyl acetate. This procedure was repeated with methanol.

\section{Bioassays}

In the bioassay procedure, extracts were dissolved in an appropriate organic solvent (the same solvent that the extracts were obtained) at a concentration of $2 \% \mathrm{~m} \cdot \mathrm{V}^{-1}$. Five milliliters of this solution was applied to disks of Whatman paper. 
Control disks were similarly prepared with pure solvent. The disks were placed in Petri - dishes and the solvent evaporated naturally. The dried disks were moistened with $2 \mathrm{~mL}$ of distillated water and 25 seeds were distributed on them. The bioassays were incubated at $25{ }^{\circ} \mathrm{C}$ with 12 hours of photoperiod.

The germination process was monitored during 15 days. Every day the seeds were counted and those, which had sprouted, were taken from the disks.

The bioassays were realized with all extracts obtained with different solvents (hexane, dichlorometane, ethyl acetate and methanol).

\section{Discharge of the residues}

Whole generated residues were submitted to chemical treatments at Laboratory of Residues from IQSC -USP, São Carlos, Brazil, that allow their further reutilization.

\section{Equipment}

CE experiments were performed on a Hewlett Packard 3D Capillary Electrophoresis, Agilent Technologies Palo Alto, CA, USA), equipped with a diode array detector (DAD). Uncoated fused silica capillary $(50 \mu \mathrm{m}$ id., $50 \mathrm{~cm}$ length to the detector, $58.5 \mathrm{~cm}$ total length) was obtained from Polymicro Technologies, Phoenix,AZ, USA. Samples were injected by pressure (50 mbar x $3 \mathrm{~s})$ and the signals were recorded with UV-Vis detection.

Every time before starting analyses the capillary was flushed with $1.0 \mathrm{~mol} \mathrm{~L}^{-1} \mathrm{NaOH}$ for $5 \mathrm{~min}$, deionized water for $10 \mathrm{~min}$ and with the running electrolyte for $15 \mathrm{~min}$. Between each run, the capillary was flushed with water for $2 \mathrm{~min}$, followed by flushing with the running electrolyte for $3 \mathrm{~min}$.

\section{Analysis conditions}

Electrolyte concentration and optimized conditions used in each protocol are described below.

-Protocol I: sodium phosphate buffer 20 mmol L-1, pH 2.5 (adjusted with phosphoric acid), $3 \mathrm{~s}$ injection at $50 \mathrm{mbar}, 20 \mathrm{kV}, 220 \mathrm{~nm}, 25^{\circ} \mathrm{C}$.

Under this condition, one expects to find compounds, which absorb in the UV-Vis region and present positive charge in $\mathrm{pH} 2.5$, basic compounds as alkaloids can be separated and identified using these conditions

- Protocol II: 3,5 dinitrobenzoate $10 \mathrm{mmol}$ $\mathrm{L}^{-1}$, CTAB 0.5 mmol.L-1 $(\mathrm{pH} 3.6), 3 \mathrm{~s}$ injection at 50 mbar, $-15 \mathrm{kV}$, detection at $254 \mathrm{~nm}, 25^{\circ} \mathrm{C}$.
This condition can be used for anionic compounds that show no absorption on the UV-Vis and present $\mathrm{pK}$ less than 5.0. In this case a chromophoric agent is used as part of the CE electrolyte. Carboxylic acids can be identified using this protocol.

-Protocol III: sodium phosphate buffer 16 mmol L-1, pH 6.5 (adjusted with phosphoric acid) with $10 \%$ of methanol, $3 \mathrm{~s}$ injection at 50 mbar, $22 \mathrm{kV}$, detection at $200 \mathrm{~nm}, 25^{\circ} \mathrm{C}$.

Using sodium phosphate, $\mathrm{pH}$ 6,5 we could separate and identify anionic compounds which absorb in UV-Vis and present $\mathrm{pK}_{\mathrm{a}}$ values smaller or near 7. Phenolic acids could be identified in these conditions.

-Protocol IV: sodium tetraborate buffer 20 mmol L-1, pH 9.4 with $15 \%$ of methanol, $3 \mathrm{~s}$ injection at $50 \mathrm{mbar}, 22 \mathrm{kV}$, detection at $350 \mathrm{~nm}, 25^{\circ} \mathrm{C}$.

Under these conditions, it is possible to detect anionic compounds that show absorption in the UV-Vis region and present $\mathrm{pK}_{\mathrm{a}}$ values less than or near to 9.4 (compounds that can be ionized in this $\mathrm{pH}$ values). Flavonoids are an important secondary metabolic class identified here because they have a hydroxyl group linked to a ring that can be "desprotonated" in high $\mathrm{pH}$ values and will migrate in anion form to the detector.

-Protocol V: sodium tetraborate buffer 20 mmol L-1, SDS $13 \mathrm{mmol} \mathrm{L}^{-1}$ and $20 \%$ of methanol (pH 9.4), $3 \mathrm{~s}$ injection at 10 mbar, 20 $\mathrm{kV}$, detection at $214 \mathrm{~nm}, 25^{\circ} \mathrm{C}$.

In this condition it can be separated neutral compounds that absorb in the UV-Vis region. These analyses are developed in the MEKC mode, where a surfactant micelar solution is the electrolyte utilized. It can be separated and identified terpenes.

All compounds were identified by comparison of the migration time, UV spectra data with the respective standards and by standard addition.

\section{Results and discussion}

Allelopathic Potential of Organic Extracts from Roots of Canavalia ensiformis.

Allelopathic potential of organic extracts from roots of Canavalia ensiformis was calculated using the equation below:

$$
I \%=\left[1-\left(\frac{G S_{\text {SAMPLE }}}{G S_{\text {CONTROL }}}\right)\right] \times 100
$$

Were: $I(\%)$ - Inhibition of seeds germination $G S_{\text {SAMPLE }}$ - seeds germinated on the Petri dishes 
where the extracts were applied.

$G S_{\text {CONTROL }}$ - seeds germinated on the Petri dishes where the extracts were not applied.

The response of the seeds to the extracts from Canavalia ensiformis is shown in Figure 1.

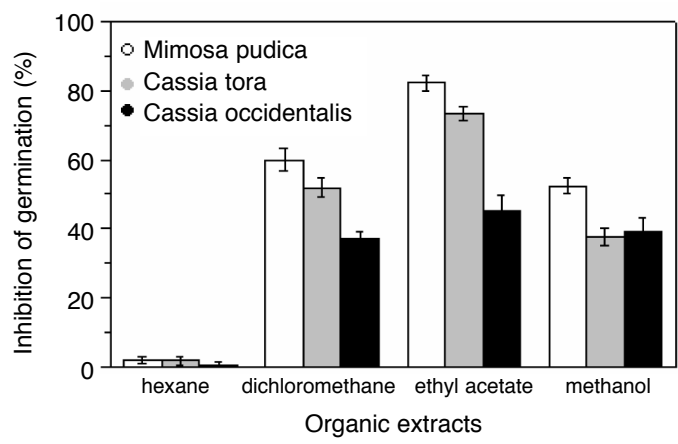

Figure 1. Inhibition of germination of the weed seeds by organic extracts from Canavalia ensiformis roots.

The extract obtained with ethyl acetate was the most efficient on the inhibition of germination 82, 73 and $45 \%$ were the results for Mimosa pudica, Cassia tora and Cassia occidentalis, respectively. Extracts obtained with methanol presented smallest activity, the inhibition values varied from 38 to $52 \%$.

Using hexanic extract in the bioassays the values reached were smaller than $5 \%$ for all seeds so, this extracts were not considered potentially allelopathic.

These results show that Canavalia ensiformis has allelopathic potential and probably the activity of this plant is due the presence of polar compounds.

Seeds of Mimosa pudica and Cassia tora were more affected by all extracts than seeds of Cassia occidentalis, which proves the specificity of the organic extracts obtained. This fact is very important because a natural herbicide have to present selectivity that are not matched by conventional herbicides.

\section{Systematic Evaluation of Secondary Compounds by Capillary Electrophoresis}

Electrophoresis protocols were considered satisfactory in order to separate and identify all the studied metabolites.

Figure 2 presents the standard mixture analyzed under the conditions of the protocols 1 , 3, 4 and 5 (direct UV-Vis detection).

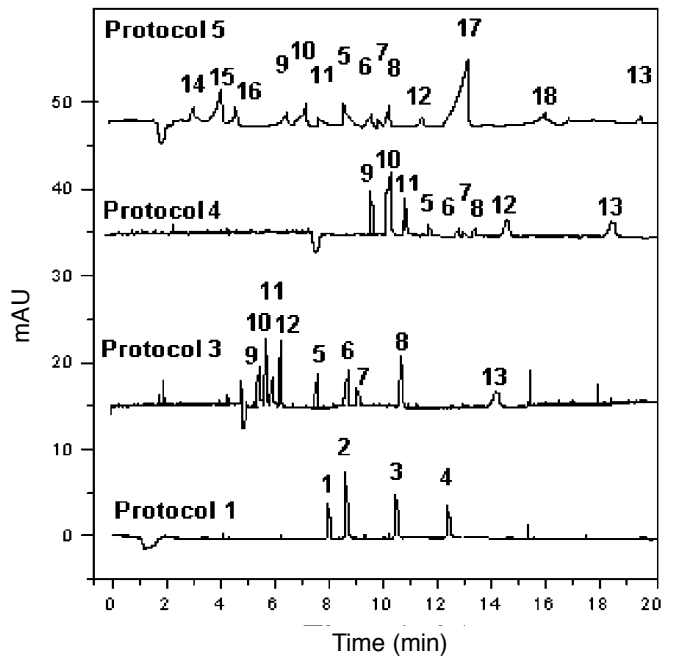

Figure 2. Standard mixture submitted to protocols 1, 3, 4 and 5, using direct UV-Vis detection.

Peak identification: ALKALOIDS: 1 - quinine; 2 - cinchonidine; 3 - pilocarpine; 4 - atropine; PHENOLIC ACIDS: 5 - chlorogenic acid; 6 - ferulic acid; 7 - cafeic acid; 8 - $p$-anisic acid; FLAVONOIDS: 9 - genistein; 10 rutin; 11 - naringenin; 12 - kaempferol; 13 - quercetin; TERPENES: 14 - nerolidol; 15 - terpineol; 16 - linalool; 17 - geraniol; 18 - $t$-anetol.

Figure 3 presents the standard mixture analyzed under the conditions of the protocol 2, used to separate and identify carboxylic acids by indirect detection.

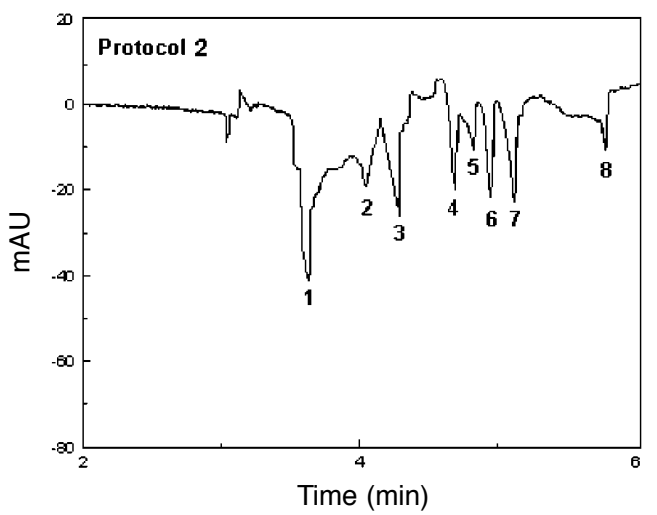

Figure 3. Standard mixture submitted to protocol 2 using indirect UV-detection.

Peak identification: CARBOXYLIC ACIDS: 1 - oxalic acid; 2 - maleic acid; 3 - malonic acid; 4 - tartaric acid; 5 - malic acid; 6 - aspartic acid; 7 - citric acid; 8 - succinic acid. 
Table 1. Compounds identified in the crude extracts by capillary electrophoresis.

\begin{tabular}{|c|c|c|c|c|}
\hline Protocols & Hexane & Dichloromethane & Ethyl acetate & Methanol \\
\hline Protocol I & n.i & n.i & atropine & atropine \\
\hline Protocol II & n.i & n.i & n.i & $\begin{array}{c}\text { oxalic acid } \\
\text { maleic acid } \\
\text { malonic acid } \\
\text { aspartic acid } \\
\text { citric acid }\end{array}$ \\
\hline Protocol III & n.i & n.i & $\begin{array}{l}\text { pherulic acid } \\
\text { cafeic acida }\end{array}$ & chlorogenic acid \\
\hline Protocol IV & n.i & n.i & n.i & $\begin{array}{c}\text { rutin } \\
\text { genistein } \\
\text { naringenin } \\
\text { kaempferol }\end{array}$ \\
\hline Protocol V & n.i. & n.i. & n.i. & n.i. \\
\hline
\end{tabular}

The results for the analyses of the crude extracts were shown in Table 1. Methanolic and ethyl acetate extracts show the major number of compounds identified. Dichloromethane extract shows activity on the bioassays however; none compound studied was identified in it.

Terpenes are neutral compounds and they were expected on hexanic extract analyzed under protocol $\mathrm{V}$, but the standards of terpenes evaluated in this work were not detected in the hexanic extracts obtained from Canavalia ensiformis roots.
Allelopathic effect of the identified compounds

Germination experiments were performed to determine the allelopathic potential of all identified compounds. The standards of each compound were dissolved in methanol at $5 \mathrm{mg} . \mathrm{L}^{-1}$ and applied in the Petri dishes following the procedure described in the Experimental section.

The values found for the inhibition of germination of the seeds are shown on Table 2.

Atropine was the most efficient in the inhibition of all seeds. Most of the carboxylic acids did

Table 2. Inhibition of germination of the seeds by the secondary compounds identified.

\begin{tabular}{lccc}
\hline Compounds & $\begin{array}{c}\text { Mimosa pudica } \\
(\% \text { of inhibition })\end{array}$ & $\begin{array}{c}\text { Cassia tora } \\
\text { (\% of inhibition })\end{array}$ & $\begin{array}{c}\text { Cássia occidentalis } \\
\text { (\% of inhibition })\end{array}$ \\
\hline atropine & 72.4 & 72.0 & 45.6 \\
oxalic acid & 0 & 0 & 0 \\
maleic acid & 0 & 0 & 0 \\
malonic acid & 0 & 0 & 0 \\
aspartic acid & 0 & 0 & 0 \\
citric acid & 11.1 & 0 & 0 \\
clorogenic acid & 37.1 & 36.4 & 15.7 \\
pherulic acid & 53.4 & 5.1 & 26.9 \\
cafeic acid & 9.1 & 6.7 & 0 \\
genistein & 36.2 & 38.8 & 13.3 \\
rutin & 31.8 & 17.6 & 0 \\
naringenin & 42.6 & 38.6 & 10.6 \\
kaempferol & 42.6 & 40.0 & 0
\end{tabular}


not presented activity, citric acid was the only one that show some activity in the germination of seeds of Mimosa pudica. The values found for phenolic acids varied from 5.1 to 53.4 when chlorogenic acid was applied in seeds of Mimosa pudica and Cassia tora. Seeds germination of Cassia occidentalis was not inhibited when it was apllied cafeic acid, rutin and kaempferol.

In general, seeds of Mimosa pudica were the most sensitive specie and Cassia occidentalis the less one. The exception happened when solution of pherulic acid was applied in the dishes. In this case Cassia tora $(5.1 \%)$ presented smaller sensitivity than Cassia occidentalis (26.9\%).

\section{Conclusions}

Canavalia ensiformis (Jack Beans) presents a strong allelopathic potential. The organic crude extracts obtained from solvents with high dielectric constants were the most efficient in the inhibition of the weed seeds germination. Seeds of Mimosa pudica M. (malícia) and Cassia tora L (mata-pasto) were more affected by the extracts than the seeds of Cassia occidentalis L. (fedegoso); this fact reveals the specificity of the organic extracts obtained.

Capillary electrophoresis protocols were highly specific, which makes it possible to identify 5 classes of compounds using the same crude extract samples and analyze them fartly (up to $20 \mathrm{~min}$ ). The use of these protocols can provide with important information about the composition of a specific plant, thus establishing an important tool for preliminary listing of possible compound groups.

Most of the compounds identified show activity in the inhibition of seeds germination. Carboxilic acids were the less efficient.

Then, Canavalia ensiformis can be considered as a source of compounds which present allelopathy properties, which after having been studied properly, can serve in the future like natural herbicides or can be used as molecular models to create more active, healthier and environmentally safer products.

\section{Acknowledgments}

We are grateful to Brazilian financial agencies FAPESP (01/14123-0) and CAPES for the financial support and to EMBRAPA Amazônia Oriental for vegetable material and seeds.

Received 04 May 2007

Accepted 23 August 2007

S. Santos, M. L. L. Moraes , M. O. O. Rezende, Potencial alelopático e avaliação sistemática de compostos secundários em extratos provenientes das raízes de Canavalia ensiformis utilizando eletroforese capilar.

Resumo: Extratos orgânicos foram obtidos a partir das raízes de Canavalia ensiformis. Tais extratos foram avaliados a fim de determinar o potencial alelopático dos mesmos na germinação das sementes das plantas daninhas: Mimosa pudica, Cassia tora e Cassia occidentalis se mostrando bastante eficazes. Posteriormente, tais extratos foram submetidos a análises sistemáticas utilizando protocolos desenvolvidos em eletroforese capilar para a determinação de algumas classes de metabólitos secundários. Os protocolos desenvolvidos se mostraram altamente específicos sendo possível identificar 5 classes de compostos utilizando os mesmos extratos brutos. Alguns compostos identificados apresentaram potencial alelopático frente às sementes de plantas daninhas estudadas.

Palavras-chave: alelopatia; eletroforese capilar; Canavalia ensiformis; raízes.

\section{References}

[1] J.B. Harbone, Introduction to ecological biochemistry, Academic Press, London, 1988.

[2] F.A. Einhelig, Handbook of natural pesticides methods, CRC Press, Florida, 2000.

[3] L.C. Mebiri, Biol. Argic. Horticult. 12 (1996) 319.

[4]. A.B.I. Dedibie, J. Nwaiwei, J. Nig. Aric. 23 (1988) 130.

[5] S.O. Duke; J. Lydon, Weed Technol. 1 (1987) 122.

[6] L. Suntornsuk, J. Pharm. Bio. Anal. 27 (2002) 679.

[7] A.G. Micke, P.E. Moraes, S.P.J. Farah, M.F.M. Tavares, J.
Chrom. A. 1004 (2003) 131.

[8] M.F.M. Tavares, Quim. Nova 16 (1996) 173.

[9] M.F.M. Tavares, M.F.M. Quim. Nova 20 (1997) 493.

[10] H.J. Issaq, Electrophoresis 20 (1999) 2190.

[11] A.N. Guzman, Capillary electrophoresis technology. Marcel Dekker, New York, 1993.

[12] L.L.M. Moraes, A.G. Micke, P.E. Moraes, M.N. Fujiya, M.F.M. Tavares, in Tyrol Congress (editor), Proceedings of $17^{\text {th }}$ International Symposium on Microescale Separation and Capillary Electrophoresis. Tyrol Congress Publishers, Innsbruck, 2004; P083. 